\title{
Procoagulant Activity of Platelets and Tissue Factor Microparticles in Behçets Disease
}

\author{
EL Desouki EL Desouki Fouda*, EL-Sayed AL Maghawri EL-Sayed**, \\ Mona Hilmy Alrayes***, Mohammed Abdel Maboud El Shennawy* \\ *Department of Internal medicine, Faculty of Medicine, Al-Azhar University(Cairo), ${ }^{* *}$ Internal medicine Al- \\ Azhar Faculty of Medicine (Damietta), and ${ }^{* * *}$ Department of Clinical Pathology, \\ Faculty of Medicine for Girls, Al-Azhar University \\ Corresponding author: Mohamed Abdel Maboud El Shennawy, e.mail: Mohamedmina936@gmail.com
}

\begin{abstract}
Background: Microparticles are found in all body fluids including peripheral blood. They play an important role in blood clot formation and increased cell aggregation.

Aim of this work: Was to evaluate the level of circulating platelet microparticles (PMP) and tissue factor microparticles (TFMP) in Behcet`s disease and to assess the relation of these procoagulant markers and Behçet's disease activity.
\end{abstract}

Patients and methods: This study included 100 persons divided to three groups; Behçet's disease (BD) group (40) patients, systemic lupus (SLE) group (40) patients as a comparative and control group (20) persons. Platelet-free plasma was ultra-centrifuged. PMPs and TFMPs were identified and enumerated with flow cytometry using anti CD61PE and CD142Percp antibodies. D-dimer was measured by ELISA.

Results: There was statistically significant increase of PMP (CD61), tissue factor MP (CD142), CD61-MFI and CD142-MFI in Behcet`s group in comparison to Control group $(\mathrm{p}<0.001)$. There was statistically significant increase of PMP and tissue factor MP in Behcet's when compared to Lupus group ( $p<0.001)$, while CD61/CD142, CD61MFI and CD142-MFI revealed no significant difference. D-dimer was significantly increased during Behcet`s and SLE disease activity ( $\mathrm{p}=0.036 \& \mathrm{p}=0.021$ respectively). Active Behcet's disease had significant increase of both CD61 and tissue factor expressing PMP (CD61/CD142) when compared to patients with inactive state $(\mathrm{p}<0.001 \&$ $\mathrm{p}=0.004$ respectively), while $\mathrm{CD} 142$ showed no significant difference $(\mathrm{p}=0.38)$. In Behcet`s group, there was significant positive correlation between CD61 and each of CD61/CD142 and D-dimer ( $\mathrm{p}=0.001)$.

Conclusion: PMP and TF MP are significantly elevated in BD in comparison to SLE. PMP, PMP expressing TF and D-dimer are markers of disease activity in both BD and SLE, while ESR and CRP are not. PMP is positively correlated to TF expressing PMP and D-dimer in BD denoting enhanced prothrombotic state. PMP, PMP expressing $\mathrm{TF}$ and D-dimer are characters of ANCA positive BD.

Keywords: Platelet microparticles, Tissue factor microparticles, Behçets` disease and Systemic lupus erythematosus

\section{INTRODUCTION}

Microparticles have received increased attention as universal markers of activation in eukaryotic cells ${ }^{(\mathbf{1})}$. MPs carry markers of the parent cell, including those induced by activation, apoptosis, cell Lysis or oxidative stress. Blood contains microparticles (MPs) derived from different cell types, including mainly platelets, red blood cells, granulocytes, monocytes, lymphocytes and endothelial cells. Overproduction of MPs has been related to various physiological and pathophysiological conditions such as cell adhesion, apoptosis, immune response, vascular function, vascular remodeling and angiogenesis, hemostasis and thrombosis, cardiovascular diseases, cancer and infections ${ }^{(2)}$.

The clinical relevance of these procoagulant MP properties has been demonstrated in various thromboembolic diseases ${ }^{(3)}$.

Dvorak and co-workers showed that several cancer cell lines release a coagulant activity that is associated with membrane vesicles. They postulated that these vesicles (i) provide a phospholipid surface to allow assembly of tenase and prothrombinase complexes, and (ii) exhibit a 'thromboplastin-like' activity, i.e. a tissue factor activity ${ }^{(4)}$.Later studies confirmed both hypotheses. Thus, TF does not only have an extravascular distribution, but can also be present within the blood where TF is associated with cell-derived vesicles ${ }^{(\mathbf{5})}$.

Circulating MPs blood levels result from the balance between their rates of release from cells and their clearance from the circulation. Changes in MP levels in circulating blood may be due to some pathological conditions .PMPs are the most abundant, representing about $70-90 \%$ of all circulating MPs ${ }^{(6)}$. A consensus protocol to measure MPs do not yet exist, flow cytometry-based detection of MPs have been shown to be a reliable and reproducible method (7).

Behçet's disease (BD) is a multisystemic vasculitis, characterized by cutaneous lesions such as aphthous stomatitis, genital ulcers, erythema nodosum-like lesions and papulopustular lesions, as well as uveitis, epididymitis, neurological symptoms, 
and involvement of vessels of all sizes, joints, and the gastrointestinal system ${ }^{(8)}$.

Behçet's disease involves both arteries and veins. According to the studies conducted in Turkey, more than $40 \%$ of Behçet patients have vascular involvement. The frequency of large-vessel involvement in Japan was 6\%. Venous involvement was more common than arterial ${ }^{(9)}$.

Arterial involvement can also be seen in forms of aneurysms, mostly on the pulmonary artery, peripheral arteries or abdominal aorta. Arterial lesions develop approximately 4 years after the initial diagnosis, with an average age of 38 and a male predominance. Pulmonary artery involvement is rather rare (5\%), presenting with either an aneurysm or thrombosis. Vasculitis causes endothelial injury, leading to formation of thrombosis. Main symptoms of pulmonary artery aneurysm are fever, chest pain, cough, dyspnea, and hemoptysis. On initial evaluation, unilateral or bilateral hilar opacities can be observed on a chest X-ray ${ }^{(10)}$.

A complex genetic background coupled to innate and adaptive immune system activation causes the diverse clinical manifestations that characterize the clinical picture in Behçet's disease ${ }^{(11)}$.

Autoimmune or autoinflammatory reactions in Behçet's disease are suggested to target primarily blood vessels, especially endothelial cells, causing the clinical presentation of vasculitis and/or thrombosis symptoms ${ }^{(12)}$.

Behçet's disease has no pathognomonic laboratory findings or histological characteristics, diagnoses are made according to clinical criteria proposed by the International Study Group for Behçet's Disease or the Behçet's Disease Research Committee of Japan ${ }^{(13)}$.The most effective management involves early diagnosis and clinical intervention with continuous follow-up. Consequently, it may be possible to reduce the risk of serious complications and socioeconomic costs due to Behçet's disease ${ }^{(14)}$.

\section{PATIENTS AND METHODS}

The present study included 40 patients diagnosed with $\mathrm{BD}$, according to the criteria of the International Study Group for Behçet's Disease ${ }^{(15)}$.They were selected from patients attended the Internal Medicine Department of Al-Azhar University Hospitals. The activity index was determined as described by Bhakta et al. ${ }^{(16)}$. In addition, 40 patients of Systemic lupus with and without thrombotic complications were included in the present work. Furthermore, 20 healthy subjects were included as a control group.

This study was approved by the Researches Ethics Committee at Faculty of Medicine, Al-Azhar University, Cairo. Informed consents were obtained from all subjects.

\section{Exclusion criteria}

Smoking, use of oral contraceptives, use of anticoagulant and/or antiplatelet drugs, uncontrolled hypertension, diabetes, hyperlipidaemia, peripheral or coronary artery disease, presence of abnormal hepatic or renal function.

\section{All patients were subjected to the following: Full history taking Detailed Clinical examination Clinically, Behcet's disease was diagnosed if the following clinical criteria were fulfilled: \\ Recurrent oral ulcerations (apthous or herpetiform) at least three times in one year}

\section{Additionally, patients must present any two of the following:}

Recurrent genital ulcerations

Eye lesions (uveitis or retinal vasculitis)

Skin lesions (erythema nodosum, pseudofolliculitis, papulopustular lesions, acneiform nodules) found in adult patients not being treated with corticosteroids Positive "pathergy test"

Laboratory investigations:

Complete blood count was performed by automated cell counter (Beckman-Coulter, CA).

ESR was determined by Westergren'smethod ${ }^{(17)}$.

CRP concentrations were determined by ELISA with a sensitivity of $0.9 \mu \mathrm{g} \mathrm{CRP} / 1$ (Sigma) ${ }^{(18)}$.

D-dimer was measured by ab (No 196269) Abcam's D-dimer in vitro SimpleStep ELISA ${ }^{\circledR}$ (EnzymeLinked Immunosorbent Assay) kit as described by manufacturer. The kit is designed for the quantitative measurement of D-dimer protein in human serum, plasma, urine, and cell culture supernatants.

Microparticles preparation for flow cytometry assay Flow cytometry analysis of PMPs and TFMPs was done by using flow cytometer BD Facscalibur, Becton Dickinson four colors at the Center for Immunology and Allergic diseases, Al-Azhar University, Cairo, Egypt.

Blood sample was immediately placed into plastic tubes containing 1/10th volume of $3.2 \%$ trisodium citrate. Cells were removed by centrifugation for two step centrifugation at $24^{\circ} \mathrm{C}$ :

$1500 \mathrm{~g}$ for 10 minutes .

$13.000 \mathrm{~g}$ for 10 minutes.

The supernatant (plasma free platelets) was stored at $-70{ }^{\circ} \mathrm{C}$ until tests were performed.

Isolation of microparticles: Microparticles were isolated after thawing plasma aliquots on melting ice by centrifugation for 7 minutes $\left(2.000 \mathrm{~g}, 25^{\circ} \mathrm{C}\right)$ then centrifugation for 10 minutes $\left(7.000 \mathrm{~g}, 25{ }^{\circ} \mathrm{C}\right)$ to pellet the microparticles (MPs). 500 $\mu$ l of plasma sample was taken to flow-cytometer tube $(5 \mathrm{ml}$ polystyrene round bottom tube), centrifuged for one 
hour $\left(17.000 \mathrm{~g}, 4{ }^{\circ} \mathrm{C}\right)$, MP-free plasma was discarded and the pellet still in round bottom of the tube ${ }^{(19)}$. For flow cytometer analysis; $200 \mu \mathrm{L}$ PBS buffer were added to the microparticles to suspend.

\section{Flow cytometry}

- The PMPs were detected by monoclonal anti-human CD61 Phycoerythrin (CD61PE) from BD kemet Egypt company, Material Number: 558818.

- The TFMPs were detected by monoclonal antihuman CD142 PerCp (CD142 Percp), catalog number: FAB10971P.

$-50 \mu \mathrm{L}$ of platelet-free plasma MPs was incubated for 30 minutes in the dark at room temperature with $20 \mu \mathrm{l}$ CD61PE and $20 \mu \mathrm{l} \mathrm{CD142} \mathrm{Percp.}$

- 200 $\mu 1$ of phosphate buffered saline (PBS) were added before immediate acquisition.

- The number of MPs present in the sample was derived by dividing the number of MPs events counted by the volume of the sample analyzed $x$ the sample volume, and adjusting for final dilution of the original blood sample ${ }^{(20)}$.

\section{Statistical analysis of data}

The collected data were analyzed by statistical package for social science (SPSS) software package, version 18 (SPSS Inc., Chicago, Illinois, USA). Quantitative data were presented as mean and standard deviation, while qualitative data were presented as number and percent distribution. For comparison between two means, the student $(t)$ test was used, while for association between categorical variables, cross tabulation was done and Chi square test was used. The Pearson correlation coefficient (r) was calculated to investigate correlation between two parameters. $\mathrm{P}$ value $<0.05$ was considered significant.

\section{RESULTS}

In Behcet's group, there was statistically significant decrease of hemoglobin, platelets, WBCs and RBCs when compared to Control group (table1).

In Behcet's group, there was statistically significant decrease of hemoglobin, WBCs and RBCs when compared to Lupus group, while platelets were significantly higher in Behcet`s group (table-2).

Regarding to inflammatory markers; ESR, CRP and D-dimer were significantly higher in Behcet's when compared to control group $(p<0.001)($ table-3).
Both ESR and CRP were significantly higher in Behcet'sgroup when compared to Lupus group. On the other hand, there was no statistically significant difference between Behcet's and Lupus groups as regard to D-dimer (table-4).

ANCA positive cases were significantly higher in Behcet's group when compared to Control group $(\mathrm{p}<0.001)$ (table-5).

As regard to micro particles when comparing Behcet's group to Control group; there was statistically significant increase of PMP (CD61), tissue factor MP (CD142), CD61-MFI and CD142MFI in Behcet`s group $(\mathrm{p}<0.001)$ (table-6).

There was statistically significant increase of PMP (CD61) and tissue factor MP (CD142) in Behcet's when compared to Lupus group $(\mathrm{p}<0.001,0.011)$, while CD61/CD142, CD61-MFI and CD142-MFI revealed no significant difference (table-7).

In the present work, D-dimer was significantly increased in patients in active disease state when compared to patients with inactive state in all studied cases $(p=0.001)$. Also D-dimer was significantly increased during of Behcet's and SLE activity ( $p=0.036 \& p=0.021$ respectively). On the other hand ESR and CRP showed no significant difference between patients with active and inactive cases (table-8).

Patients with active Behcet's disease had significant increase of both CD61 and tissue factor expressing PMP (CD61/CD142) when compared to patients with inactive state $(p<0.001 \& p=0.004$ respectively), while CD142 showed no significant difference $(\mathrm{p}=0.38)$. In active Lupus patients, there was significant increase of CD61, CD142, CD61/CD142, CD61-MFI and CD142- MFI when compared to patients' inactive state $(\mathrm{p}<0.001$, $\mathrm{p}<0.001,0.003, \mathrm{p}<0.001, \mathrm{p}<0.001)($ table-9).

In Behcet's group, there was significant positive correlation between CD61 and CD61/CD142 and Ddimer $(p=0.001)$; while there was significant negative correlation between CD61 and ESR ( $\mathrm{p}=0.042)$ (table10).

In active Behcet's subgroup, there was significant positive correlation between D-dimer and WBCs $(\mathrm{p}=0.007)$ (table-11).

In Behcet's group, there was statistically significant increase of D-dimer, CD61 and CD61/CD142 in ANCA positive when compared to ANCA negative subgroups $(0.002,0.041,0.009)$ (table-12). 
Table (1): Comparison between Behcet`s and Control groups as regard to CBC findings

\begin{tabular}{|c|c|c|c|c|c|c|}
\hline & \multicolumn{2}{|c|}{ Behcet`s } & \multicolumn{2}{|c|}{ Control group } & \multirow[t]{2}{*}{$\mathrm{T}$} & \multirow[t]{2}{*}{$\mathrm{P}$} \\
\hline & Mean & SD & Mean & SD & & \\
\hline Hemoglobin $(\mathrm{gm} / \mathrm{dl})$ & 10.18 & 1.28 & 12.16 & 0.35 & 8.20 & $<0.001 *$ \\
\hline Platelets $\left(\mathrm{X} 10^{\wedge} 3 \mathrm{cell} / \mathrm{ml}\right)$ & 221.17 & 34.36 & 278.50 & 44.55 & 6.08 & $<0.001 *$ \\
\hline WBCs $\left(X 10^{\wedge} 3\right.$ cell $\left./ \mathrm{ml}\right)$ & 3.31 & 0.61 & 4.97 & 0.84 & 9.55 & $<0.001 *$ \\
\hline RBCs (X 10^6 cell $/ \mathrm{ml})$ & 4.21 & 0.19 & 4.40 & 0.22 & 3.75 & $<0.001 *$ \\
\hline
\end{tabular}

SD: Stander deviation. $\quad *$ Significant $(\mathrm{p}<0.05)$

Table (2): Comparison between Behcet`s and Lupus groups as regard to CBC findings

\begin{tabular}{|c|r|r|r|r|r|r|}
\hline & \multicolumn{3}{|c|}{ Behcet`s } & \multicolumn{2}{|c|}{ Lupus } & \multirow{2}{*}{ P } \\
\cline { 2 - 5 } & Mean & SD & Mean & SD & & \\
\hline Hemoglobin $(\mathrm{gm} . / \mathrm{dl})$ & 10.18 & 1.28 & 11.20 & 1.22 & 3.62 & $0.001^{*}$ \\
\hline Platelets (X 10^3 cell/ml) & 221.17 & 34.36 & 199.07 & 20.29 & 3.50 & $0.001^{*}$ \\
\hline WBCs (X 10^3 cell/ml) & 3.31 & 0.61 & 4.63 & 0.32 & 1.98 & $<0.001^{*}$ \\
\hline RBCs (X 10^6 cell/ml) & 4.21 & 0.19 & 4.34 & 0.22 & 2.67 & $0.009^{*}$ \\
\hline
\end{tabular}

CBC complete blood count. RBCs red blood cells. WBCs white blood cells. * Significant ( $<<0.05)$.

Table (3): Comparison between Behcet`s and Control group as regard to inflammatory markers

\begin{tabular}{|c|c|c|c|c|c|c|}
\hline & \multicolumn{2}{|c|}{ Behcet`s } & \multicolumn{2}{|c|}{ Control group } & & \\
\hline & Mean & SD & Mean & SD & & \\
\hline ESR (mm/ $1^{\text {st }}$ hour $)$ & 69.40 & 23.81 & 7.13 & 1.25 & 16.50 & $<0.001 *$ \\
\hline CRP (mg \%) & 14.7500 & 6.96 & 4.83 & 0.79 & 8.92 & $<0.001 *$ \\
\hline D-dimer $(\mu \mathrm{g} / \mathrm{ml})$ & 326.00 & 99.20 & 125.63 & 31.97 & 11.97 & $<0.001 *$ \\
\hline
\end{tabular}

ESR erythrocyte sedimentation rate. CRP C - reactive protein. D-dimer fibrin degradation product. * Significant $(\mathrm{p}<0.05)$

Table (4): Comparison between Behcet`s and Lupus group as regard to inflammatory markers

\begin{tabular}{|c|c|c|c|c|c|c|}
\hline & \multicolumn{2}{|c|}{ Behcet's } & \multicolumn{2}{|c|}{ Lupus } & \multirow[t]{2}{*}{$\mathrm{T}$} & \multirow[t]{2}{*}{$\mathrm{P}$} \\
\hline & Mean & SD & Mean & SD & & \\
\hline ESR $\left(\mathrm{mm} / 1^{\text {st }}\right.$ hour $)$ & 69.40 & 23.81 & 27.27 & 15.38 & 9.39 & $<0.001 *$ \\
\hline CRP (mg \%) & 14.75 & 6.96 & 10.47 & 5.04 & 3.14 & $0.002 *$ \\
\hline D-dimer $(\mu \mathrm{g} / \mathrm{ml})$ & 326.00 & 99.20 & 296.02 & 69.52 & 1.56 & $0.12(\mathrm{~ns})$ \\
\hline
\end{tabular}

ESR erythrocyte sedimentation rate. CRP C - reactive protein. D-dimer fibrin degradation product. (ns) Nonsignificant.

Table (5): Comparison between Behcet`s and control group as regard to ANCA

\begin{tabular}{|c|c|c|c|c|c|c|c|}
\hline & \multicolumn{4}{|r|}{ Group } & \multirow{2}{*}{\multicolumn{2}{|c|}{ Statistics }} \\
\hline & & \multicolumn{2}{|c|}{ Behcet`s } & \multicolumn{2}{|r|}{ Control } & & \\
\hline & & $\mathrm{n}$ & $\%$ & $\mathrm{~N}$ & $\%$ & $\mathrm{X} 2$ & $\mathrm{P}$ \\
\hline \multirow[t]{2}{*}{ ANCA } & Positive & 36 & $90.0 \%$ & 0 & $0.0 \%$ & \multirow[t]{2}{*}{55.58} & \multirow[t]{2}{*}{$<0.001^{*}$} \\
\hline & Negative & 4 & $10.0 \%$ & 30 & $100.0 \%$ & & \\
\hline
\end{tabular}

ANCA Antineutrophil cytoplasmic antibodies. * Significant $(\mathrm{p}<0.05)$

Table (6): Comparison between Behcet's and Control groups as regard to platelets micro particles and tissue factor micro particles

\begin{tabular}{|r|r|r|r|r|r|r|}
\hline & \multicolumn{3}{|c|}{ Behcet`s } & \multicolumn{2}{|c|}{ Control group } & \multicolumn{2}{|c|}{ Statistics } \\
\cline { 2 - 7 } & Mean & SD & Mean & SD & T & P \\
\hline CD61/ml & 36111.1 & 14222.1 & 3739.13 & 1248.58 & 14.32 & $<0.001^{*}$ \\
\hline CD142/ml & 13280.6 & 5320.4 & 1255.06 & 662.384 & 14.15 & $<0.001^{*}$ \\
\hline CD61/CD142 & 16189.2 & 12968.1 & 18465.06 & 5220.948 & 1.01 & 0.31 \\
\hline CD61-MFI & 13.90 & 9.38 & 7.07 & 0.98 & 4.56 & $<0.001^{*}$ \\
\hline CD142-MFI & 4.51 & 1.32 & 3.45 & 0.35 & 4.27 & $<0.001^{*}$ \\
\hline
\end{tabular}

MFI Mean Fluorescent Intensity 
Table (7): Comparison between Behcet`s and Lupus groups as regard to platelets micro particles and tissue factor micro particles

\begin{tabular}{|r|r|r|r|r|r|r|}
\hline & \multicolumn{2}{|c|}{ Behcet`s } & \multicolumn{2}{c|}{ Lupus } & \multicolumn{2}{|c|}{ Statistics } \\
\cline { 2 - 7 } & Mean & SD & Mean & SD & T & P \\
\hline CD61/ml & 36111.1 & 14222.1 & 23595.3 & 6377.9 & 5.07 & $<0.001^{*}$ \\
\hline CD142/ml & 13280.6 & 5320.4 & 10541.4 & 3981.3 & 2.60 & $0.011^{*}$ \\
\hline CD61/CD142 & 16189.2 & 12968.1 & 12709.5 & 11546.5 & 1.26 & 0.22 \\
\hline CD61-MFI & 13.90 & 9.38 & 15.96 & 9.47 & 0.97 & 0.33 \\
\hline CD142-MFI & 4.51 & 1.32 & 4.87 & 1.34 & 1.20 & 0.23 \\
\hline
\end{tabular}

MFI Mean Fluorescent Intensity

Table (8): Comparison between active and inactive subgroups in both Behcet's and SLE groups as regard to inflammatory markers

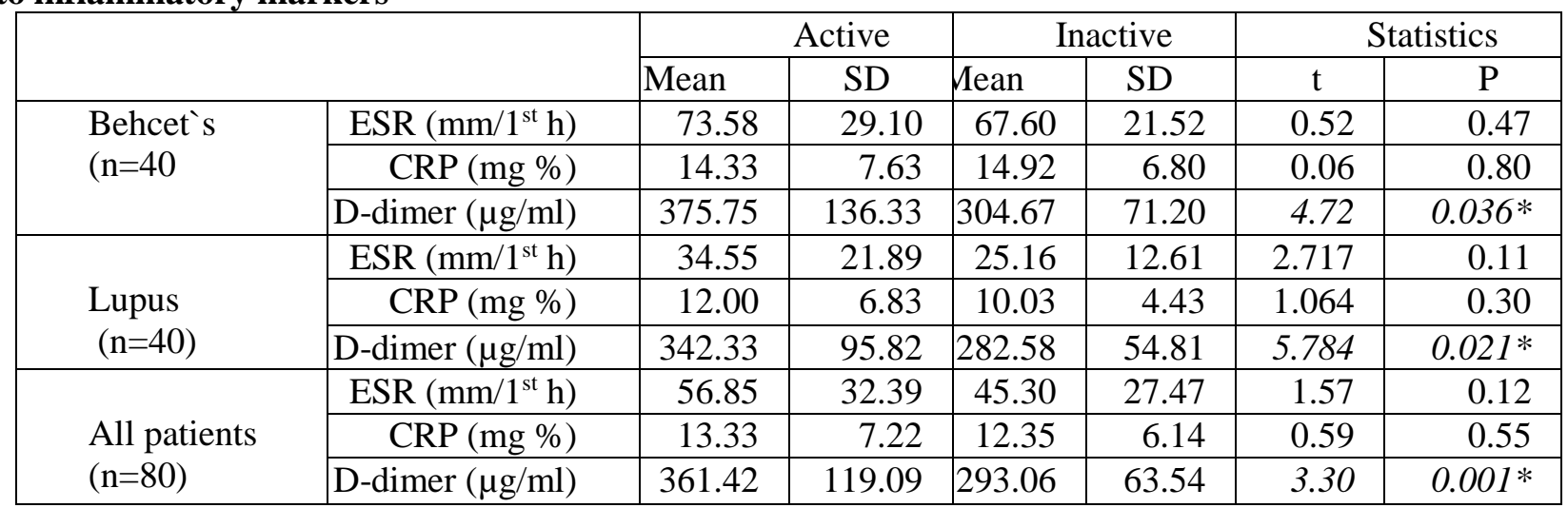

ESR erythrocyte sedimentation rate. CRP C - reactive protein. D-dimer fibrin degradation product. RBCs red blood cells. WBCs white blood cells

Table (9): Comparison between active and inactive subgroups in both Behcet's and SLE groups as regard to microparticles

\begin{tabular}{|c|c|c|c|c|c|c|}
\hline \\
\hline & & & Mean & SD & $\mathrm{T}$ & $\mathrm{P}$ \\
\hline \multirow[t]{10}{*}{ Behcet`s $(n=40)$} & \multirow[t]{2}{*}{$\mathrm{CD} 61 / \mathrm{ml}$} & Active & 49270.50 & 12758.96 & \multirow[t]{2}{*}{4.78} & \multirow[t]{2}{*}{$<0.001 *$} \\
\hline & & Inactive & 30471.42 & 10765.61 & & \\
\hline & \multirow[t]{2}{*}{ CD142/ml } & Active & 14424.75 & 5935.16 & \multirow[t]{2}{*}{0.88} & \multirow{2}{*}{0.38} \\
\hline & & Inactive & 12790.28 & 5070.07 & & \\
\hline & \multirow[t]{2}{*}{ CD61/CD142 } & Active & 24966.00 & 17310.97 & \multirow[t]{2}{*}{3.09} & \multirow[t]{2}{*}{$0.004 *$} \\
\hline & & Inactive & 12427.71 & 8480.62 & & \\
\hline & \multirow{2}{*}{ CD61-MFI } & Active & 13.85 & 6.98 & \multirow[t]{2}{*}{0.001} & \multirow[t]{2}{*}{0.98} \\
\hline & & Inactive & 13.92 & 10.36 & & \\
\hline & \multirow[t]{2}{*}{ CD142-MFI } & Active & 4.61 & 1.22 & \multirow[t]{2}{*}{0.31} & \multirow[t]{2}{*}{0.75} \\
\hline & & Inactive & 4.47 & 1.38 & & \\
\hline \multirow{10}{*}{$\begin{array}{l}\text { Lupus } \\
(\mathrm{n}=40)\end{array}$} & \multirow[t]{2}{*}{$\mathrm{CD} 61 / \mathrm{ml}$} & Active & 32367.00 & 6620.71 & \multirow[t]{2}{*}{7.00} & \multirow[t]{2}{*}{$<0.001 *$} \\
\hline & & Inactive & 21048.67 & 3377.63 & & \\
\hline & \multirow[t]{2}{*}{$\mathrm{CD} 142 / \mathrm{ml}$} & Active & 14655.00 & 5142.91 & \multirow[t]{2}{*}{4.20} & \multirow[t]{2}{*}{$<0.001 *$} \\
\hline & & Inactive & 9347.22 & 2646.44 & & \\
\hline & \multirow[t]{2}{*}{ CD61/CD142 } & Active & 22449.00 & 14752.14 & \multirow[t]{2}{*}{3.19} & \multirow[t]{2}{*}{$0.003 *$} \\
\hline & & Inactive & 9882.00 & 8863.81 & & \\
\hline & \multirow[t]{2}{*}{ CD61-MFI } & Active & 26.50 & 11.01 & \multirow[t]{2}{*}{4.70} & \multirow[t]{2}{*}{$<0.001 *$} \\
\hline & & Inactive & 12.90 & 6.42 & & \\
\hline & \multirow[t]{2}{*}{ CD142-MFI } & Active & 6.24 & 1.36 & \multirow[t]{2}{*}{4.11} & \multirow[t]{2}{*}{$<0.001 *$} \\
\hline & & Inactive & 4.47 & 1.06 & & \\
\hline
\end{tabular}

MFI Mean Fluorescent Intensity 
Table (10): Correlation between platelet micro particles (CD61) and other studied parameters in Behcet's group

\begin{tabular}{|c|c|c|}
\hline & $\mathrm{R}$ & $\mathrm{P}$ \\
\hline CD142/ml & 0.263 & 0.101 \\
\hline CD61/CD142 & 0.486 & $0.001^{*}$ \\
\hline Age & 0.093 & 0.570 \\
\hline Hemoglobin & 0.114 & 0.485 \\
\hline Platelets & 0.015 & 0.925 \\
\hline WBCs & -0.054 & 0.742 \\
\hline RBCs & 0.232 & 0.151 \\
\hline ESR & -0.323 & $0.042^{*}$ \\
\hline CRP & -0.254 & 0.114 \\
\hline D-dimer & 0.515 & $0.001^{*}$ \\
\hline
\end{tabular}

ESR erythrocyte sedimentation rate. CRP C - reactive protein. D-dimer fibrin degradation product. RBCs red blood cells. WBCs white blood cells.

Table (11): Correlation of platelet microparticles (CD61), tissue factor microparticles CD142 and Ddimer with other studied variables in active Behcet's $(n=12)$

\begin{tabular}{|c|r|r|r|r|r|r|}
\hline & \multicolumn{2}{|c|}{ CD61 } & \multicolumn{2}{|c|}{ CD142 } & \multicolumn{2}{|c|}{ D-dimer } \\
\cline { 2 - 7 } & $\mathrm{r}$ & $\mathrm{p}$ & $\mathrm{R}$ & $\mathrm{P}$ & $\mathrm{R}$ & $\mathrm{P}$ \\
\hline CD61 & & & 0.08 & 0.78 & 0.30 & 0.33 \\
\hline CD142 & 0.08 & 0.78 & & & -0.10 & 0.74 \\
\hline CD61/CD142 & 0.47 & 0.12 & -0.27 & 0.39 & 0.14 & 0.65 \\
\hline Age & 0.10 & 0.74 & -0.37 & 0.23 & -0.07 & 0.82 \\
\hline Hemoglobin & 0.52 & 0.07 & 0.22 & 0.48 & 0.39 & 0.20 \\
\hline Platelets & 0.18 & 0.57 & 0.13 & 0.68 & -0.41 & 0.17 \\
\hline WBCs & 0.42 & 0.16 & -0.07 & 0.81 & 0.73 & $0.007 *$ \\
\hline RBCs & 0.30 & 0.33 & 0.28 & 0.36 & 0.35 & 0.26 \\
\hline ESR & -0.51 & 0.08 & -0.54 & 0.06 & -0.45 & 0.14 \\
\hline CRP & -0.53 & $0.07 *$ & -0.56 & 0.05 & -0.30 & 0.32 \\
\hline D-dimer & 0.30 & 0.33 & -0.10 & 0.74 & & \\
\hline
\end{tabular}

ESR erythrocyte sedimentation rate. CRP C - reactive protein. D-dimer fibrin degradation product. RBCs red blood cells. WBCs white blood cells.

Table (12): Comparison between ANCA positive and ANCA negative Behcet`s patients as regard studied parameters

\begin{tabular}{|c|c|c|c|c|c|c|}
\hline & & & \multicolumn{2}{|r|}{ ANCA } & \multirow[t]{3}{*}{$\mathrm{T}$} & \multirow[t]{3}{*}{$\mathrm{P}$} \\
\hline & \multicolumn{2}{|r|}{ Positive } & & Negative & & \\
\hline & Mean & SD & Mean & SD & & \\
\hline Age & 41.19 & 10.55 & 40.25 & 10.90 & 0.16 & 0.87 \\
\hline Hemoglobin & 10.19 & 1.32 & 10.07 & 1.00 & 0.22 & 0.83 \\
\hline Platelets & 221.47 & 35.76 & 218.50 & 20.46 & 0.25 & 0.81 \\
\hline WBCs & 3.30 & 0.63 & 3.40 & 0.43 & 0.41 & 0.69 \\
\hline RBCs & 4.21 & 0.20 & 4.22 & 0.18 & 0.10 & 0.92 \\
\hline ESR & 69.19 & 24.80 & 71.25 & 13.76 & 0.25 & 0.80 \\
\hline CRP & 14.83 & 7.12 & 14.00 & 6.16 & 0.25 & 0.81 \\
\hline$D$-dimer & 332.69 & 102.356 & 265.75 & 18.04 & 3.46 & $0.002 *$ \\
\hline CD61 & 37038.00 & 14613.662 & 27769.50 & 5908.60 & 2.42 & $0.041 *$ \\
\hline CD142 & 13497.00 & 5526.561 & 11333.25 & 2458.07 & 1.40 & 0.20 \\
\hline$C D 61 / C D 142$ & 17010.75 & 13396.843 & 8795.25 & 3374.77 & 2.93 & $0.009 *$ \\
\hline
\end{tabular}

* Significant $(\mathrm{p}<0.05)$ 


\section{DISCUSSION}

The present study was designed to investigate the link between the level of circulating platelet microparticles and tissue factor microparticles as prothrombotic markers and disease activity in Behcet's diseases.

Behcet's patients showed high significant lower values of hemoglobin and total leukocytes count with significant higher platelets count when compared to SLE patients. Jung et al. (21) reported that the severity of thrombocytopenia can be a useful independent prognostic factor to predict survival and response to treatment in patients with SLE.

As regard to inflammatory markers, both ESR and CRP were significantly higher in Behcet's group when compared to lupus group. D-dimer showed no significant difference (table 8). This findings might throw light on the more extended tissue damage in Behcet's disease. Berlit $^{(22)}$ stated that the laboratory findings suggestive of a systemic vasculitis included an acute inflammatory response with raised ESR and increased values of CRP, while anemia was a frequent associated finding.

In the present work, the $\%$ of cases positive for ANCA were significantly increased in both Behcet's disease and lupus groups when compared to control group. However, the difference between both groups was statistically not significant.

Daniel et al. (23) demonstrated an elevation in neutrophil microparticles (NMPs) and PMPs in adult patients with ANCA associated vasculitis during active disease compared to controls.

A retrospective study on lupus nephritis patients done by Wang $\boldsymbol{e t} \boldsymbol{a l}{ }^{(24)}$ they found that the prevalence of $\mathrm{p}$ ANCA was not rare. Also they reported that, more multisystem damage occurred in ANCA positive than in ANCA negative lupus nephritis patients. However, ANCA positive lupus nephritis patients showed high scores on the pathological chronic index, outlining ANCA as an independent risk factor for poor renal outcomes in lupus nephritis patients.

The platelet microparticles and tissue factor microparticles were significantly elevated in Behcet's disease group when compared to both control and SLE groups (tables 9, 10). CD61 MFI and CD142 MFI were significantly elevated in Behcet's disease group when compared to the control. So the increased density of these molecules could contribute to the potent procoagulant activity of these microparticles

in Behcet's disease.
El-Desouki et al. ${ }^{(25)}$ found high significant increase in both platelet microparticles (CD42a) and endothelial microparticles (CD105) in active vasculitis secondary to Behcet's disease in comparison with the control group.

Benameur et al. ${ }^{(26)}$ stated that the physiological and pathophysiological roles of MPs were unclear. They can be beneficial or deleterious, depending on situations and composition. Since inflammation is characterized by interactions among platelets, leukocytes and endothelial cells, levels of MPs from these cells were elevated in pathologies such as vascular and immune diseases.

Martinez et al. ${ }^{(27)}$ reported that the presence of a higher number of spontaneous PMPs in BD patients with previous thrombosis can, at least partly, be attributed to the fact that these patients show shear stress changes in their circulation. This change may be sufficient to stimulate platelets and thus lead to the formation of micro-aggregates.

The D-dimer level was significantly increased with disease activity in both Behcet's and SLE groups in comparison with the inactive state (table8).

In Behcet's patients with activity, the circulating platelet microparticles and platelet microparticles expressing tissue factor were significantly increased in comparison with inactive Behcet's patients ( $<<0.001 \& \mathrm{p}=0.004$ respectively). The circulating tissue factor microparticles showed no difference as regard activity in Behcet's patients. While in active SLE patients all; circulating platelet microparticles, tissue factor microparticles and platelet microparticles expressing tissue factor together with the density of expression of CD61 and CD142 molecules were significantly increased. These data might indicate different cytokines, platelet agonists and/or initiators player in the pathogenesis of Behcet's disease and SLE.

In Behcet's disease, the circulating platelet microparticles were positively correlated with the platelet microparticles expressing tissue factor and the D-dimer $(\mathrm{p}=0.001)$. In SLE group, the circulating platelet microparticles were positively correlated with the tissue factor microparticles, platelet microparticles expressing tissue factor and the D-dimer $(\mathrm{p}=0.000, \mathrm{p}=0.000$ \& $\mathrm{p}=0.004$ respectively). These data could illustrate that the platelet microparticles are the main player regarding the prothrombotic sate in SLE. Many mechanisms may play a role in the increased level 
of PMPs as excessive platelet stimulant, excessive platelet apoptosis or decreased clearance.

Lood et al. ${ }^{(28)}$ reported that, in SLE platelet activation induces the production of copious amounts of PMPs. Lopez et al. ${ }^{(29)}$ found that PMP levels are correlated with SLE disease activitysimilar to the finding in the present study. Pereira et al. ${ }^{(30)}$ found no relation at all, but they used a much smaller cohort, and this small number of subjects can explain their results. McCarthy et al. ${ }^{(31)}$ report suggested that PMP levels were correlated with endothelium-independent vasodilatation in SLE (a marker of vascular tone function), suggesting a potential use of PMPs as biomarker of organ dysfunction.

Lopez et al. ${ }^{(29)}$ had revealed relevant alterations in the composition of the circulating MP pool in SLE patients. Above all, patients displayed increased counts of MPs derived from platelets, monocytes and T lymphocytes, in line with MP characteristics previously identified in patients with autoimmune diseases, including SLE ${ }^{(32)}$.

El-Desouki et al. $^{(25)}$ found in their study that; EMPs and PMPs were independent factors that seem to be correlated to the vascular insult. Both were highly sensitive and specific for diagnosis and monitoring vacuities and might substitute ANCA test especially in ANCA negative vacuities.

\section{CONCLUSION}

PMP and TF MP are significantly elevated in BD in comparison to SLE. PMP, PMP expressing TF and Ddimer are markers of disease activity in both BD and SLE, while ESR and CRP are not. PMP is positively correlated to TF expressing PMP and D-dimer in BD denoting enhanced prothrombotic state. PMP, PMP expressing TF and D-dimer are characters of ANCA positive BD.

\section{REFERENCES}

1. Ahn YS (2005): Cell-derived microparticles: 'miniature envoys with many faces'. J. Thromb Haemost., 3: 884-891.

2. Flaumenhaft $R$, Dilks J, Richardson J (2009): Megakaryocyte-derived microparticles: direct visualization and distinction from platelet-derived microparticles. Blood, 113: 1112-1121.

3. Leroyer AS, Anfosso F, Njock SM (2010): Endothelial derived microparticles: Biological conveyors at the crossroad of inflammation, thrombosis and angiogenesis. Thromb. Haemost., 104: 456-63.

4. Dvorak HF, Quay SC, Orenstein NS, Dvorak AM, Bitzer AM (1981): Tumor shedding and coagulation. Science, 212 (4497):923-4.

5. Manly DA, Boles J, Mackman N (2011): Role of tissue factor in venous thrombosis. Annu. Rev. Physiol., 73:51525.
6. Enjeti AK, Lincz LF, Seldon M (2008): Microparticles in health and disease. Semin. Thromb. Hemost., 34: 683-691.

7. Piccin A, Murphy WG, Smith OP (2007): Circulating microparticles: pathophysiology and clinical implications. Blood. Rev., 21: 157-71.

8. Mat MC, Sevim A, Fresko I, Tüzün Y(2014): Behçet's disease as a systemic disease. Clinics. in Dermatology, 32: 435-442.

9. Ideguchi H, Suda A, Takeno M, Ueda A, Ohno S, Ishigatsubo Y (2011): Disease evolution of clinical manifestations. Medicine. (Baltimore), 90: 125-132.

10. Mat MC, Sevim A, Fresko I, Tüzün Y (2014): Behçet's disease as a systemic disease. Clinics. in Dermatology, 32: 435-442.

11. Gül A, Ohno S. Genetics of Behçet's disease. In: Yazici Y, Yazici H (2010): Behçet's Syndrome. 1st Ed. New York: Springer.

12. Lee KH, Chung HS, Kim HS, Oh SH et al. (2003): Human alpha-enolase from endothelial cells as a target antigen of anti-endothelial cell antibody in Behçet's disease. Arthritis. Rheum., 48: 2025-35.

13. Kurokawa MS, Yoshikawa H, Suzuki N(2004): Behçet's disease. Semin. RespirCrit. Care. Med., 25:557-68.

14. Cho SB, Cho S, Bang D (2012): New Insights in the Clinical Understanding of Behçet's Disease. Yonsei. Med. J., 53(1):35-42.

15.Davatchi F, Assaad-Khalil S, Calamia KT et al. (2014): The International Criteria for Behcet's Disease (ICBD): a collaborative study of 27 countries on the sensitivity and specificity of the new criteria. https://www.ncbi.nlm.nih.gov/pubmed/23441863

16. Bhakta BB, Brennan P, James TE, Noble BA, Silman AJ (1999): Behcet's disease: evaluation of a new instrument to measure clinical activity. Rheumatology, (Oxford), 38:728-733.

17.Pawlotsky Y, Goasguen J, Guggenbuhl $P$ et al. (2004): Sigma ESR: an erythrocyte sedimentation rate adjusted for the hematocrit and hemoglobin concentration. Am. J. ClinPathol., 122(5):802-10.

18. Ribeiro MA (1997): Levels of C-reactive protein in serum samples from healthy children and adults in São Paulo, Brazil. BCr-arezailciatinveJopurrontaelin of Medical. and Biological. Research, 30: 1055-1059.

19. Borgan $B$ and Dillon $M$ (2004): $\quad$ Endothelial microparticles and diagnosis of vasculitides. Internal. medicine, 43(12): 1115-1110.

20. Shet A (2008): Characterizing blood microparticles: Technical aspects and challenges. Vascular. Healthand. Risk Managemen., 4(4) 769-774.

21.Jung JH, Soh MS, Ahn YH et al. (2016): Thrombocytopenia in Systemic Lupus Erythematosus clinical manifestations, treatment and prognosis in 230 patients. Medicine. (Baltimore), 95: e2818.

22. Berlit A(2010): Diagnosis and treatment of cerebral vasculitis. Ther. Adva Neural Disord., 3(1):29-42. 
23. Daniel L, Fakhouri F, Joly D et al. (2006): Increase of circulating neutrophil and platelet microparticles during acute vasculitis and hemodialysis. Kidney. Int., 69:1416-23.

24. Wang Y, Huang X, Cai J et al. (2016): Clinicopathologic characteristics and outcomes of lupus nephritis with antineutrophil cytoplasmic antibody: a retrospective study. Medicine. (Baltimore), 95: e2580.

25. El-Desouki E, Ahmed M, Alrayes M (2014): Circulating Endothelial and Platelet Microparticles for Diagnosis and Monitoring Vasculitis. Allergy. Clin. Immunol., 133(2).

26. Benameur T, Andriantsitohaina R, Martínez MC (2009): Therapeutic potential of plasma membrane derived microparticles. Pharmacological. Reports, 61:49-57.

27. Martinez M, Ricart J, Ruiz-Aja S et al. (2007): Platelet Activation and Red Blood Cell Phosphatidylserine Exposure Evaluated by Flow Cytometry in Patients with Behcet's Disease: Are They Related to Thrombotic Events? Pathophysiol. Haemost. Thromb., 36:18-22.

28. Lood C, Tydén H, Gullstrand B, and Nielsen CT et al. (2016): Decreased platelet size is associated with platelet activation and anti-phospholipid syndrome in Systemic Lupus Erythematosus. Rheumatology, doi: 10. 1093/ rheumatology/kew437.

29. López P, Rodríguez-Carrio J, Caminal- Montero L, Suárez A (2017): Circulating microparticle subpopulations in systemic lupus erythematosus are affected by disease activity. Int. J. Cardiol., 236:13844.

30.Pereira J, Alfaro G, Goycoolea M, Quiroga T et al. (2005): Circulating platelet-derived microparticles in systemic lupus erythematosus. Association with increased thrombin generation and procoagulant state. Thromb. Haemost., 95:94-9.

31. McCarthy EM, Moreno-Martinez D, Wilkinson FL et al. (2017): Microparticle sub-populations are potential markers of disease progression and vascular dysfunction across a spectrum of connective tissue disease. BBA. Clin., 7:16-22.

32. Nielsen C, Østergaard O, Stener L et al. (2012): Increased IgG on cell-derived plasma microparticles in Systemic Lupus Erythematosus is associated with autoantibodies and complement activation. Arthritis. Rheum., 64 (4) 1227-1236. 